\title{
El golpe de Rojas y el poder de los militares
}

\author{
Rojas' coup d'etat and the power of army men
}

Adolfo León Atehortúa Cruz ${ }^{1}$

El ascenso paulatino de los militares en la política, luego del 9 de abril de 1948, llevó finalmente al poder a Gustavo Rojas Pinilla en 1953. El golpe de estado fue anunciado, consentido y propiciado por parte de la élite civil. No obstante, una vez en el poder, Rojas empezó a alejarse de la dirigencia tradicional y de los partidos, y convirtió a su gobierno en una dictadura de carácter más personal que incluso militar. Su propósito no resistió la arremetida de la élite. Gómez y Lleras lideraron el pacto que finalmente condujo a la caída de Rojas, en 1957, sin una resignación total por parte de los militares que, fraccionados por momentos, intentaron proseguir en el poder o restaurar a Rojas. El presente artículo describe, interroga y analiza estos hechos bajo la óptica del poder de los militares.

\section{PALABRAS CLAVE:}

Rojas Pinilla, golpe de estado, dictadura, militares, historia política Colombia.

\section{ABSTRACT}

The rising of army men into politics, after April the 9th, 1948, finally gave the power to Gustavo Rojas Pinilla, in 1953. The coup d'etatwas announced, consented and favored on the part of the civil elite. Nevertheless, once in power, Rojas moved away from the traditional leadership and parties, and turned his government into a dictatorship of more personal character, different even from military style. His purpose did not resist the elite's attacks. Gómez and Lleras headed the pact that finally concluded in Rojas' fall, in 1957. This came without the total resignation on the part of the army men who, sometimes divided, tried to continue in power or restore Rojas. The present paper describes questions and analyzes those facts under the military point of view.

KEYWORDS:

Rojas Pinilla, coup d'etat, dictatorship, soldiers, Political Colombian History.

Artículo recibido 25 de Febrero de 2010 y aprobado el 30 de abril de 2010

1 Profesor Titular del Departamento de Ciencias Sociales de la Universidad Pedagógica Nacional. adolfoateortua@cable.net.co 


\section{Un golpe anunciado}

La necesidad de superar la desbordante situación de violencia en que se encontraba el país, de recuperar para el Estado la funcionalidad de sus instituciones y de restaurar la legitimidad del sistema, produjo el golpe militar del 13 de junio de 1953.

Todos lo pedían o esperaban. De manera directa o indirecta, abierta o embozada, la intervención del Ejército empezó a ser apreciada por distintos grupos políticos y económicos. Alfonso López Pumarejo, en el Partido Liberal, postuló con certeza que si la violencia no se detenía, podría devorar al país. Estaba seguro de que el freno a la violencia no era posible con Laureano Gómez en el poder: el periódico "El Siglo" trataba a los liberales de "bandoleros" y el gobierno pedía a la dirección del partido que definiera su rechazo a ellos². El conflicto, en lugar de resolverse, parecía extremarse.

Los industriales tampoco estaban a gusto con el gobierno de Laureano Gómez. Según lo descubrió Eduardo Sáenz porque los industriales sentían que las medidas para combatir la inflación habían precipitado "una verdadera crisis con efectos deflacionistas" 3 . En la Asamblea Nacional, realizada en Cali en abril de 1951, la Asociación Nacional de Industriales - ANDI- insistió en la "proximidad del colapso" y su alarma fue trasmitida por el Embajador americano al Departamento de Estado4. Rafael Urdaneta, quien reemplazó temporalmente a Laureano cuando éste dejó la presidencia por motivos de salud, hizo todo lo posible para satisfacer las demandas de los industriales y visitó las instalaciones de algunas empresas para constatar su estado. Aunque la mejoría económica fue reconocida un año después, los industriales continuaron preocupados por la violencia y la "lucha a muerte entre los partidos". A la queja se sumó la Federación Nacional

2 El Siglo, enero 28 de 1952.

3 Asociación Nacional de Industriales -ANDI-. Acta 481, marzo 31 de 1951. Citada por Eduardo Sáenz Rovner. (2002). Colombia años 50. Industriales, política y diplomacia, p. 103. Bogotá: Universidad Nacional.

4 Embajador Beaulac al Secretario de Estado. Abril 27 de 1951. Archivo Nacional de Estados Unidos en adelante, ANEU. FW 721.00/42751. de Comerciantes -FENALCO-, quien agregó a ello su descontento por la limitación del crédito y la prohibición de las importaciones 5 .

La oposición de Gómez a la candidatura de Mariano Ospina, oficializada en abril de 1953, confirmó el temor sobre la continuidad del régimen y acercó a los militares a una importante fracción de los conservadores. Ospina Pérez era el único dirigente de ese partido que podía ganar el apoyo liberal y convocar con legitimidad y fuerza la transformación de la situación reinante. Gilberto Alzate lo apoyaba con la esperanza de sucederlo y los liberales esperaban regresar, al menos, a la legalidad plena y ¿por qué no?, a un nuevo "gobierno de unidad nacional". Ospina, al mismo tiempo, estaba dispuesto a conceder la amnistía a todos los guerrilleros y a propiciar políticas económicas que favorecieran a los gremios de la producción y el comercio. Si Gómez combatía la candidatura de Ospina, la opción por la intervención militar adquiría mayor vigencia: sólo ella podría recuperar el poder político de los partidos y detener la violencia.

En la Embajada Americana, la perspectiva del golpe tampoco era desconocida. La Embajada no sólo no descartaba su posibilidad concreta a partir de 1952, sino que ... en realidad, lo esperaba: "el deterioro del orden público mortifica en grado extremo a los militares", se dijo en un comunicado ${ }^{6}$. Los primeros rumores llegaron a oídos del embajador en abril de ese año. Ante la crisis ministerial desatada en esa fecha, Urdaneta pensó en nombrar militares en los ministerios y gobernaciones. De esta manera, el presidente encargado buscaba adelantarse a los propósitos de algunos oficiales y neutralizar su disgusto con posiciones burocráticas. La decisión retrocedió por la intervención de Alzate Avendaño, quien detentaba alguna influencia en los altos mandos.

5 Véase, Carlos H. Urán. Rojas y la manipulación del poder. Bogotá: Carlos Valencia Editores, 1983, pp. 51 y 52.

6 Véase Despacho n. ${ }^{\circ} 953$ del 21 de abril de 1952. Reporte de la Embajada Americana en Colombia al Departamento de Estado-ANEU-. 
Más que los militares, a la Embajada le preocupaban los guerrilleros. Aunque su triunfo era poco probable y remoto, la posibilidad de alcanzar centros vitales de población y su prolongada existencia contribuía a la inestabilidad del gobierno y acercaba la posibilidad de un movimiento militar o de un golpe cívico-militar para tomarse el poder ${ }^{7}$. Por esa razón, la Embajada coincidía con la propuesta de López Pumarejo y los guerrilleros: amnistía general y comités bipartidistas en todos los departamentos afectados para investigar cada hecho de violencia. Sin embargo, en lugar de expresar su respaldo en forma oficial y directa, el embajador intentó divulgar su pensamiento a través del Nuncio Apostólico, quien se mostraba de acuerdo. La Embajada estaba convencida de que, si el gobierno no se mostraba más flexible, el riesgo de una infiltración comunista en la guerrilla era cada vez mayor. Es más: los guerrilleros del Llano practicaban ya, de manera espontánea e inadvertida, algunos "principios comunistas".

Para Estados Unidos, la certeza del golpe apareció con claridad a raíz de algunas conversaciones entre Alzate Avendaño y diplomáticos norteamericanos. El dirigente político tenía la convicción de que sólo a través de una amnistía completa era posible alcanzar el final de la violencia en el país. A ello debía seguir el levantamiento del estado de sitio, la eliminación de la censura y los esfuerzos de ambos partidos por elaborar un sistema de garantías electorales. Como ello era prácticamente imposible con el gobierno de Gómez y Urdaneta, este debía entregar su lugar a otro que pudiera lograrlo9.

Tras los hechos del 6 de septiembre de 1952, la posibilidad de un golpe militar se hizo aún más evidente. Al menos para el embajador norteamericano, su emergencia era irreversible. No sólo parecía clara la inspiración, dirección y complacencia de los incendios contra las casas de los dirigentes liberales y la prensa por parte de la fracción conservadora dirigida por Álvaro Gómez y Jorge Leyva, sino que,

7 Ibídem.

8 Despacho n. $^{\circ} 125$ de 13 de agosto de 1952. Reporte de la Embajada Americana en Colombia al Departamento de Estado -ANEU-.

9 Despacho n. ${ }^{\circ} 57$ del 23 de julio de 1952. Reporte de la Embajada Americana en Colombia al Departamento de Estado -ANEU-. abrumados por la magnitud de la situación, un grupo de oficiales retirados, en unión con otros de servicio activo, empezaron a preparar un golpe con el regreso del General Rojas Pinilla. Por eso se exigió su retorno y se consultó la decisión con Ospina y Alzate, quienes se mostraron de acuerdo. Según el embajador, Alzate pretendía alcanzar el poder en las elecciones inmediatas que los autores del golpe convocaran ${ }^{10}$.

Para constatar los rumores, el 12 de septiembre de 1952 un funcionario de la embajada se reunió con Alzate. En criterio de este último, los ataques del 6 de septiembre eran "la angustiosa salida" del laureanismo para cerrar la posibilidad de un acuerdo liberal con la candidatura de Ospina Pérez. En lugar de otorgar garantías a los dirigentes liberales y cambiar su gabinete, el gobierno extremaba las políticas de fuerza. Con las dificultades del orden público como pretexto, la Asamblea Constituyente elegiría a Jorge Leyva como próximo presidente. Para Alzate, entonces, la situación del país se degradaba hasta la anarquía. Las retaliaciones del bandolerismo no se hicieron esperar y por ello, no se excluyó la posibilidad de una guerra civil. Agotados todos los intentos por la búsqueda de una salida pacífica, no se pudo descartar un golpe militar ${ }^{11}$.

Al finalizar 1952, la eventualidad de un golpe de estado no procedía solo de la Embajada en Colombia. El Departamento de Estado observaba al gobierno como una "dictadura oligárquica" frente a la cual "cabría preguntarse si el general Rojas Pinilla y el ejército continuarían dándole pleno respaldo". La frase final era sumamente concluyente: "Rojas y Alzate han sido buenos amigos en el pasado"12.

El periódico "Diario de Colombia", dirigido por Alzate Avendaño, convirtió a Rojas en sujeto de mención y halagos constantes. La frase "General, ¡salve usted la patria!” se incluyó en sus páginas y apareció en los manifiestos ${ }^{13}$. Hijo de General y

10 Telegramas $n .{ }^{\circ} 149$ y 112 del 10 y 11 de septiembre de 1952, respectivamente. (1998).Citados por David Fernando Varela S. Documentos de la Embajada,pp.172-173. Bogotá: Planeta.

11 Despacho n. ${ }^{\circ} 236$ del 15 de septiembre de 1952. Ibíd, p. 174.

12 Memorando del 19 de diciembre de 1952. Ibíd, p. 176.

13 Diario de Colombia, mayo 9 de 1953. 
sobrino de altos oficiales, Alzate se preciaba de su "ancestro guerrero" e intentaba utilizar sus parentescos. El cardenal Crisanto Luque, máximo jerarca de la iglesia católica, visitó los cuarteles y pidió que "los militares se prepararan para el golpe de estado"14. Según dijo Alzate Avendaño: "Todo estaba previsto" para el golpe. Si Gómez intentaba posesionarse o destituir a Rojas Pinilla, se caía ${ }^{15}$. Según Alfredo Vásquez Carrizosa: "La idea del golpe era un secreto a voces" 16.

Incluso el presidente estaba enterado. La desconfianza de Laureano Gómez hacia Gustavo Rojas Pinilla tenía antecedentes en dos fuentes. La primera, cuando el presidente Ospina Pérez pasó por encima de los coroneles Carlos Perdomo y Miguel Ángel Hoyos para ascender a Rojas y nombrarlo director del Ejército. Más antiguos que Rojas en el cuerpo castrense, los dos oficiales tenían superior derecho al importante cargo. Ospina ascendió a Rojas un día antes que a Perdomo y Hoyos, y lo convirtió en general con 24 horas más antiguo que los otros ${ }^{17}$. Esta medida, adicional a las preferencias que Ospina Pérez había demostrado con el oficial a partir del 9 de abril de 1948, lo señalaba ante Gómez como "ospinista” acérrimo. Así se confirmó además cuando respaldó el cierre del Congreso y evitó una conspiración planeada contra Ospina dos días antes de la elección de Gómez como presidente ${ }^{18}$.

La segunda fuente era el general Régulo Gaitán. Seguidor y amigo íntimo de Gómez, quien transmitió su desconfianza frente a Rojas. El raudo paso de este último como director del Ejército a Ministro

14 Gustavo Rojas Pinilla. (1993). “Las guerrillas en el Llano y otras cosas más", tomo II, p.145. En: Revista de Historia, vol. 1, n. ${ }^{\circ}$, agosto de 1975, p. 7. Bogotá: Banco de la República - Uniandes.

15 Véase Abelardo Forero. (1993). Momentos y perfiles de la historia de Colombia. Bogotá: Banco de la República, Uniandes.

16 Alfredo Vásquez. (1992). Historia crítica del Frente Nacional, p.75. Bogotá: Foro Nacional por Colombia.

17 Véase Ricardo Bayona. (1984). Recuerdos de un ochentón, pp.245246. Bogotá: Editorial Nelly.

18 Sobre esta conspiración militar no existe información de archivo ni de prensa. Es el propio Rojas quien da razón de ella: "la sublevación iba a tener lugar en diferentes guarniciones. A mí me correspondió tomar precauciones para evitar ese golpe de Estado o golpe de cuartel, cambiando algunos comandantes, y también tropas". Rojas Pinilla ante el Senado. Bogotá: Periódico el Excélsior, 1959. p. 486. de Correos y Telégrafos, se debió a confrontaciones con los generales Bayona Posada y Sánchez Amaya, merced a las ínfulas y deseos de poder de Rojas, quien emitía órdenes al Ejército sin tener en cuenta al Estado Mayor. Régulo Gaitán fue un intrigante permanente contra Rojas.

Tal desconfianza motivó la primera decisión de Gómez que molestó a Rojas. Jefe del Estado Mayor en 1950 y Comandante General de las Fuerzas Militares en 1951, Gómez decidió, a través de Urdaneta, separarlo del cargo y nombrarlo Representante de Colombia en la Junta Interamericana de Defensa, para confiarle a Régulo Gaitán la dirección de las Fuerzas Militares ${ }^{19}$. Rojas comprendió la estrategia y recibió el apoyo de sus subalternos. La tropa se acuarteló y Rojas se entrevistó con Urdaneta para exponer las causas de su recelo. El cargo no era para el general de más alta graduación, sino para un coronel, como había sucedido siempre. Urdaneta desestimó la existencia de propósitos diferentes al contar con un general en Washington, que además dominaba el inglés y podría colaborar en la adquisición de armamento. La negativa de Rojas para trasladarse a Washington fue aplacada con un doble nombramiento como consejero militar de la embajada, algunos dólares adicionales en gastos de representación, una importante comitiva de ayudantes, y desplazamientos a Corea según su gusto ${ }^{20}$.

Después de ejercer el cargo en mención, Rojas Pinilla regresó a Colombia el 25 de septiembre de 1952 y dijo a su arribo: "Vengo a trabajar por la paz y la seguridad de todos”. Luego recibió múltiples homenajes de militares retirados, suboficiales y oficiales ${ }^{21}$. En diciembre viajó a los Llanos con el propósito de visitar las guarniciones militares. En su concepto, encontró "total adhesión al Ejército" y un "dominio de la legitimidad" cada vez mayor ${ }^{22}$.

19 El Siglo, abril 16 de 1951.

20 Véase Decretos 908 de 1951 y 449 de 1952 y El Siglo, marzo 2 de 1951. Rojas viajó a Japón y Corea "para entregar la bandera de las Naciones Unidas al Batallón Colombia" y fue condecorado en Estados Unidos "por su contribución a la lucha contra el comunismo". El Siglo, junio 27, septiembre 27, octubre 6 y noviembre $18 \mathrm{de}$ 1951.

21 El Siglo, septiembre 25 y 26, octubre 14 y 24 de 1952.

22 Ibídem, noviembre 11, 13 y 14 de 1952. 
Laureano realizó, entonces, un nuevo intento por alejar a Rojas del país y le ofreció un viaje a Alemania para inaugurar los vuelos de Avianca en la ruta Bogotá-Frankfurt. En la escalerilla del avión, varios oficiales le pidieron desistir del viaje porque durante su ausencia sería llamado a calificar servicios. Al descender, los subalternos tiraron sus gorras al cielo y celebraron con vítores la decisión del General Rojas se hizo consciente de su poder y pidió a Urdaneta el cambio del ministro de guerra José María Bernal, quien fue reemplazado por Lucio Pabón Núñez, recomendado por el mismo General.

Según Rojas, cuando Laureano se enteró de su permanencia en el país, decidió atacarlo a través del periódico "El Siglo". El relato del General, no confirmado por otras fuentes, constituye, de ser cierto, un hecho grave y concreto de ruptura:

...Hablé con el gerente y le dije: "Les prohibo que vuelvan a hablar de las Fuerzas Armadas o les cierro el periódico". “¿Le cierra el periódico al doctor Laureano Gómez?", y le respondí: "Sí, le cierro el periódico". Al día siguiente mandé un oficial con tropa: "Revise la edición, si hay algo contra las Fuerzas Armadas, decomísela”. Y evidentemente, venía una catilinaria contra mí23.

Para entonces, la división del Partido Conservador se hallaba protocolizada. En la efeméride del 9 de abril, Ospina lanzó su candidatura a la reelección que fue respondida por Laureano con una vibrante reprensión. El gobierno postulaba a Jorge Leyva y no estaba dispuesto a aceptar una nueva administración de Ospina Pérez. Consciente de la división, Rojas ejecutó un nuevo acto que desafió a Laureano: ofreció un banquete de gala en la Escuela Militar el 22 de mayo de 1953 y entregó su bastón de mando al designado Urdaneta. La obediencia del Ejército, en tal suerte, se depositaba en Urdaneta y no en Gómez. El discurso, sin embargo, fue más elocuente que el simbolismo del acto:

23 Véase: Gustavo Rojas Pinilla. "Reportaje". Revista de Historia, vol. I, n. ${ }^{\circ} 1,1975$, p. 16. ...la lealtad inquebrantable de las Fuerzas Armadas $[\ldots]$ se acrecienta y reafirma con el peligro y mientras más poderosa sea la responsabilidad que os corresponda asumir y necesitéis de mayor independencia para gobernar, tened la seguridad de que la fuerza de las armas, representada por los generales y por los comandantes de todos los grados aquí presentes [...] rodea vuestra persona y respalda las actuaciones que buscan con dignidad la concordia nacional y el imperio de la justicia y de la ley...24.

El hecho precedió a la detención y tortura del empresario Felipe Echavarría, cuya libertad inmediata pidió Gómez, pero fue desatendida por Rojas y el Ejército. Gómez retomó la presidencia, citó a Consejo de Ministros y ordenó el retiro de Rojas. Como el Ministro de Guerra no quiso aceptar la orden y renunció, se nombró en su reemplazo a Jorge Leyva. El general Régulo Gaitán asumiría el cargo de Rojas.

Rojas Pinilla daba por supuesta la medida de Laureano. Antes de que ocurriera viajó a su finca en Melgar, pero pidió a sus subalternos que le enviaran un avión en caso de algún suceso extraordinario. Existen muchas versiones acerca de los hechos y no es del caso confrontarlas o detenernos a su examen ${ }^{25}$. Lo previsto del suceso, sin embargo, salta a la vista con el testimonio de Bertha Hernández, la esposa de Ospina Pérez. Al conocer que Gómez se había presentado en el Palacio Presidencial, se trasladó al Batallón Caldas y preguntó por el coronel Navas Pardo:

24 Citado por María Eugenia Rojas. (2000). Rojas Pinilla, mi padre. Bogotá: Panamericana, p. 93.

25 Consúltese, por ejemplo: Arturo Alape. La paz, la violencia, testigos de excepción. (1985). Bogotá: Planeta. César Ayala Diago. El discurso de la conciliación: análisis cuantitativo de las intervenciones de Gustavo Rojas Pinilla entre 1952-1959. Anuario Colombiano de Historia Social y de la Cultura, 1990-1991. Bogotá: Universidad Nacional, Departamento de Historia. N. ${ }^{\circ}$ 18 y 19. María Eugenia Rojas. Gustavo Rojas Pinilla, mi padre. Alejandro Galvis. (1976). Memorias de un político centenarista. Bucaramanga: Impresores colombianos. Silvia Galvis y Alberto Donadío. El jefe supremo. (1988). Bogotá: Planeta. Alberto Montezuma. Comisión Instructora. El proceso contra Gustavo Rojas Pinilla ante el congreso de Colombia. Documentos compulsados y compilados por Gastón Valencia. (1960). Bogotá: Imprenta Nacional. Carlos Villar Borda. (1953). El presidente Libertador. Bogotá: Iqueima. 
Estamos listos -me dijo-, pero no puedo hacer nada sin la orden de mi General. Entonces fue cuando me enteré de que Rojas Pinilla no estaba en Bogotá, pero que ya venía en camino. "Vamos a llamar a todos los comandos", le dije: "Sí -me contestó-, "pero no desde aquí, pues este teléfono está controlado". La respuesta del coronel Iván Berrío, jefe de la Escuela Militar, y de los otros comandos fue: "estamos listos" 26.

La posición de Rojas, sin embargo, no fue muy coherente. Hizo citar a Leyva al Batallón Caldas y allí ordenó su detención y fusilamiento junto al general Régulo Gaitán y sus acompañantes, el general Gustavo Berrío y los coroneles Ospina y Abondano ${ }^{27}$. Sin embargo, acto seguido se trasladó al Palacio Presidencial y le ofreció el poder a Urdaneta. "A mí no me interesa el gobierno", le dijo. Pero Urdaneta contestó que sólo aceptaría la jefatura del Estado si Gómez renunciaba. En lugar de proceder militarmente, Rojas ordenó, entonces, buscar o esperar a Laureano, pero el problema era que no aparecía por ninguna parte.

La indecisión de Rojas Pinilla, dice uno de sus biógrafos, llegó a exasperar los ánimos de algunos de los presentes. Los oficiales de las diferentes fuerzas deseaban fervorosamente que su comandante y líder no diera más rodeos y tomara el poder. Uno de los ansiosos asistentes de aquella noche, que no pudo mantener la discreción y el silencio ante la irresolución y titubeos del general en esos dramáticos instantes del Palacio de la Carrera fue el coronel de la Fuerza Aérea Alberto Pauwels, dijo: "Lamento mucho, mi general, pero usted se toma el poder o nos lo tomamos nosotros, porque de aquí en adelante nos van a joder a todos"28.

Luego, la intervención de Lucio Pabón fue definitiva. Observó que, con el paso del tiempo, "algunos militares comenzaban a inquietarse":

26 María Clara Ospina. (1988). Doña Bertha. Bogotá: Planeta.

27 Según el testimonio de Rojas, fue su propia hija, María Eugenia, quien le hizo desistir del propósito.

28 Jorge Serpa Erazo. (1999). Rojas Pinilla. Una historia del siglo XX, pp. 19, 194. Bogotá: Planeta.
Le escuché a un capitán Benítez que decía: "carajo, si a mi General le faltan pantalones, aquí hay que buscar a otro tipo". Y un coronel, paisano mío que andaba en esas, se dirigió a mí y me dijo: "doctor Pabón, ¡qué carajo! Nosotros lo apoyamos si Usted asume el mando". Me fui donde Rojas y le dije: "Carajo, hay que tomar medidas. De pronto esto se desquicia y yo no sé qué va a pasar", y me dijo: "no, esperemos". Y me fui y busqué a Urdaneta y le dije: "mire lo que está pasando, asuma”. Él decía que no...

Le dije a Rojas... "aquí no hay más remedio, sino que tú asumas el poder, si no va a haber el reinado de la anarquía". Abrí la puerta del despacho donde estaban reunidos el doctor Ospina y el doctor Urdaneta conversando, y les dije: "vengo a comunicarles que el general Rojas acaba de asumir la Presidencia de la República”. El doctor Ospina se levantó y con un acento marcadamente antioqueño me dijo: "Pues ante los hechos cumplidos, no hay más remedio en casos como este, que aceptarlo". Les dije: "Me parece que ustedes deben ser los primeros en hacerse presentes y ofrecerle respaldo". Me llevé a los dos hasta el sitio donde estaba Rojas y lo sorprendí diciéndole: "El doctor Ospina y el doctor Urdaneta vienen a ofrecerte el respaldo al saber que has asumido la presidencia”. Rojas si más no sabe qué hacer. El general Berrío Muñoz comenzó a aplaudir y aplaudió toda la gente y así quedó elegido Rojas, muy democráticamente. Le ofrecen el respaldo, acepta ante la negativa de Urdaneta y la desaparición de Laureano. Me dicen que le prepare una alocución. Y comienza el diálogo en torno de cómo quedará constituido el gabinete22.

La prueba reina de que Gómez esperaba el golpe, no sólo se encuentra en su desaparición del 13 de junio, ya que se dedicó a la panadería en casa de su consuegro. Está, sobre todo, en su pasaporte: el suyo y los de su familia fueron expedidos y sellados con visas diplomáticas el 10 de junio. Siete días después

29 Citado por Arturo Alape. (1985). La paz, la violencia, testigos de excepción, p. 114. Bogotá: Planeta. La versión de Pabón es corroborada, en lo fundamental, por Urdaneta. Según éste: “Pabón creó el hecho, al comunicar públicamente que Rojas asumía el mando". Véase: Arturo Abella. (1973). Así fue el 13 de junio, p.84. Bogotá: Aquí Bogotá. 
viajaron a Nueva York y se iniciaron los trámites para dotar a los hermanos Enrique y Álvaro Gómez de visas de trabajo en Estados Unidos ${ }^{30}$. El propio Álvaro Gómez dijo después, desde el exilio, que el golpe "estaba decidido desde hacía por lo menos un mes y estaba prácticamente dado" ${ }^{31}$. Para el Departamento de Estado, el golpe de Rojas "tenía el apoyo conservador y la mirada benévola de los liberales; podría significar el regreso de Colombia a la democracia y no sería peor que el de Gómez con respecto a la persecución de los protestantes" 32 .

\section{El golpe de rojas: ¿el poder de los militares?}

El derrocado presidente, Laureano Gómez, no comprendió que los límites de su autoritarismo lindaban con los intereses del Estado y de grupos privilegiados históricamente consolidados. Tampoco entendió que toda la estructura del sistema peligraba si continuaba su política de represión y desafío contra los guerrilleros liberales. Entonces, inspiradas por la oposición conservadora, respaldadas por Ospina Pérez cuya candidatura presidencial había vetado Gómez, impulsadas por Alzate y con el beneplácito de la élite liberal cuyos líderes se encontraban en el exilio, las Fuerzas Armadas en cabeza del general Gustavo Rojas Pinilla consumaron el golpe de Estado que la dirigencia civil les pidió a gritos.

Los militares asumieron el poder sin proyecto de gobierno, sin programa, sin perspectiva propia. $\mathrm{Al}$ rechazar lo que consideraron una afrenta contra su comandante y sus fuerzas, se encontraron de cara al gobierno porque los civiles a quienes se lo ofrecieron no quisieron aceptarlo. Osaron quebrantar la Constitución porque, una vez dado el primer paso, ya no tenían alternativa. Como dijo Rojas, tuvieron que "hacerse cargo del gobierno del país"33. Sin embargo, tal como coinciden los testimonios, fueron

30 David Fernando Varela S., op. cit, p. 216.

31 Álvaro Gómez H. (1999). Pensando en tí, Margarita, p. 98. Bogotá: Fundación Álvaro Gómez Hurtado.

32 Memorando del asistente del Secretario de Estado para Asuntos Inter-americanos, al Secretario de Estado. Washington, junio 15 de 1953. ANEU. 721.02/6-1553.

33 El Tiempo, junio 13 de 1957. los civiles y no los uniformados quienes dijeron la última palabra el 13 de junio de 1953. Incluso el discurso con el cual Rojas anunció a los colombianos su decisión de asumir el gobierno fue redactado por un civil: Lucio Pabón Núñez.

Los militares no estaban preparados para tomarse el poder ni lo buscaron: se lo encontraron. La mejor prueba de ello es la manera como se nombró al gabinete ministerial y su composición misma. De acuerdo con el comandante de la FAC, coronel Alberto Pauwels, la designación de los ministros "fue una encerrona de Ospina dominando al general Rojas: Ospina se aprovechó de la situación y le nombró todo el gabinete al general Rojas"34. En efecto, según coinciden los testimonios, la nominación fue hecha por Ospina y Alzate en reunión con Rojas. Se entregaron algunas carteras a los militares y las demás se reasignaron a los ministros de Gómez y Urdaneta; a ospinistas y laureanistas que pasaron al gobierno de Rojas sin inmutarse y a los políticos conservadores que Ospina sugirió. La influencia de Ospina fue tan decisiva que incluso el general Gustavo Berrío, quien había acompañado al general Régulo Gaitán y a Jorge Leyva al Batallón Caldas con el objeto de reconocerlos como superiores, fue puesto preso y estuvo a punto de ser fusilado, pero terminó nombrado ministro. Berrío había sido el Comandante del Batallón Guardia Presidencial durante el gobierno de Ospina y era su amigo íntimo. Según Arturo Abella, "uno solo de los altos funcionarios del gobierno quedó por fuera: el presidente titular Laureano Gómez" ${ }^{35}$. El propio Alzate terminó decepcionado: Ospina le ganó el pulso frente a Rojas y optó por aceptar su retiro a la Embajada en España ${ }^{36}$. Para algunos oficiales, con el gabinete designado, Rojas resultaba "más conservador que militar" 37.

34 Alberto Pauwels. Reportaje realizado y citado por Jorge Serpa Erazo. op. cit., p. 196.

35 Arturo Abella. Así fue el 13 de junio. (1973), p. 52. Bogotá: Ediciones Aquí Bogotá,

36 Según Antonio Escobar, Alzate Avendaño fue el único de los participantes civiles en el golpe que quedó insatisfecho: “...estaba fuera de sí. ¿De qué le servía el golpe de cuartel? La revuelta no había sido para él, como lo creyó inicialmente". En el salón de los virreyes. Testimonio civil de un golpe militar. Bogotá: Kelly, 1957. p. 101.

37 Gabriel Puyana García. "Vivencias de un ideal”. (2001), p.146. En: Relatos que pueden ser historia. Bogotá: Editora Guadalupe. 
A pesar del gabinete $100 \%$ conservador, los siguientes anuncios del nuevo gobierno militar auguraron la reconciliación nacional: indulto y amnistía para detenidos políticos y alzados en armas, libertad de prensa, diálogo entre los partidos y "restablecimiento de las condiciones necesarias para realizar elecciones puras" 38 . La Asamblea Nacional Constituyente le reconoció el carácter presidencial a Rojas y éste lo asumió investido de legitimidad. Las palabras de Darío Echandía, históricamente presentes, definieron la acción de Rojas como un "golpe de opinión":

No fue vuestro gesto el producto de la ambición rapaz, sino el abnegado sentido del deber. Tomasteis el mando en virtud de un golpe de opinión, pues vuestros esfuerzos no fueron encaminados a destruir un estado de derecho sino a establecerlo, no a imponer la fuerza sobre la legalidad sino a cambiar la anarquía por el orden ${ }^{39}$.

La guerrilla liberal del Llano respondió al llamado del gobierno y cesó hostilidades el 22 de junio de 1953. Su segunda ley, promulgada cuatro días antes, murió con su autor, el abogado Alvear Restrepo, en circunstancias no muy claras y en medio de la negociación para deponer las armas. El 7 de julio, 500 combatientes de Antioquia, al mando de Juan de Jesús Franco, entregaron sus armas ante el general Pío Quinto Rengifo, nombrado por Rojas gobernador de ese departamento. Las entregas siguieron en cadena hasta que más de dos mil hombres, encabezados por Guadalupe Salcedo, rindieron filas y sueños al gobierno militar. A cambio, sólo algunos recibieron un crédito que pagaron totalmente en breve tiempo.

La libertad de prensa no llegó a estrenarse. A sólo dos semanas del nuevo gobierno, la Oficina de información y propaganda del Estado -ODIPE- determinó la continuación de la censura ${ }^{40}$. Poco después quedó al arbitrio del gobierno en una ley que la Embajada

38 El Tiempo, junio 13 de 1957.

39 Ibídem, julio 25 de 1953.

40 Silvia Galvis y Alberto Donadío. (1988). El Jefe Supremo, p.265. Bogotá: Planeta.
Americana calificó de "mal redactada y vaga", "destinada a silenciar la oposición al régimen"41.

La reestructuración del poder judicial fue anunciada por Rojas con el reemplazo de la Corte Suprema de Justicia. El Partido Liberal aprobó la medida porque ganó con ella la posibilidad de recuperar altas posiciones en las funciones del Estado: la mitad de los magistrados designados, incluidos Antonio Rocha y Darío Echandía, fueron liberales ${ }^{42}$. Para Alzate, por el contrario, era peligroso que el poder judicial quedara bajo tutela del ejecutivo ${ }^{43}$.

Sin embargo, la luna de miel entre Rojas, los partidos políticos y la prensa -a excepción del periódico "El Siglo"-, continuó sin mayores tropiezos. Ni siquiera la masacre contra los estudiantes durante los días 8 y 9 de junio de 1954, logró modificar las actitudes de la élite política frente al gobierno militar. Por el contrario, con respecto al asesinato de los estudiantes, dijo el periódico "El Tiempo":

Comprendemos que de esta situación, profundamente deplorable, no puede culparse jamás al gobierno que tantas pruebas ha dado de su voluntad de concordia y que ha hecho de la paz, de la libertad y de la justicia, emblema de sus actos ${ }^{44}$.

41 Embajada de Estados Unidos al Departamento de Estado, octubre 28 de 1954. ANEU. 721.32/10-2854, RG. 59.

42 El Espectador, noviembre 30 de 1953.

43 Diario de Colombia, noviembre 30 de 1953.

44 El Tiempo, junio 10 de 1954. La investigación adelantada por los agentes de seguridad del gobierno ubicó la responsabilidad de la masacre en "agentes provocadores del comunismo y del laureanismo". Con base en ese informe, la justicia concluyó que la "causa próxima" residía en la "provocación grave y agresiva que algunos estudiantes hicieron a la policía el día 8, y, al ejército, el 9 de junio", y que la "causa remota" debería buscarse en la "instigación de agentes enemigos del orden que buscan a todo instante producir el cambio brusco de las actuales instituciones". Consúltese Pedro Luis Belmonte. Antecedentes históricos del 8 y 9 de junio. Bogotá: Imprenta Nacional, 1954. En ese sentido, puede afirmarse con sarcasmo que la investigación pudo ahorrarse. Al día siguiente de los hechos el general Duarte Blum afirmó a El Espectador que "comunistas y laureanistas buscaban la caída del gobierno" y los señaló como responsables de la masacre. Cabe la pregunta: ¿acaso los manifestantes dispararon? Como corolario, la Universidad Nacional tuvo por primera y única vez en su historia un rector militar: José Manuel Agudelo, coronel, entonces titular de la cartera de comunicaciones. Sobre el contingente militar que disparó contra los estudiantes, el general Raúl Martínez Espinosa aclara que no se trató del "Batallón Colombia". Sus destacamentos regresaban al país una vez cumplido su servicio en guerra y eran licenciados 
La reelección de Rojas fue aprobada por la Asamblea Nacional Constituyente en 1954. Aunque Rojas prometió la dejación del poder "una vez se devuelvan al país los valores de la democracia”, el hecho originó los primeros choques entre el liberalismo y el presidente. La Asamblea decidió su conformación paritaria y colocó en manos del gobierno la elección de 22 representantes liberales. De una lista suministrada por las directivas del Partido Liberal y compuesta por 152 nombres, Rojas escogió 15 y eligió los otros 7 según su albedrío. Para los dirigentes liberales, "la reelección de Rojas pudo ser más elegante" 45 . En las siguientes sesiones, la Asamblea aprobó el voto femenino y, basándose en las normas impulsadas por el general McCarthy en Estados Unidos, decretó la ilegalización del "comunismo internacional" 46 .

Poco a poco el presidente reelegido se fue alejando de sus socios. Minoritario en la Asamblea, debido a los miembros que participaban en ella por fuera sus directrices, el liberalismo decidió su retiro de los altos cargos y mostró su disgusto por la suspensión de elecciones y el reemplazo de las Asambleas De-

tan pronto se efectuaba el proceso de desacuartelamiento. No conservaban entidad orgánica ni eran asignados a otras unidades. Los oficiales y suboficiales se distribuían en los cuerpos de tropa del país, pero ninguno actuó en la mañana del 9 de junio. El último cuerpo compacto de Ejército arribó al país el 30 de noviembre de 1954. Según Valencia Tovar, la fracción militar que recibió la orden de contener la manifestación, la componían soldados traídos de diferentes unidades del país. Dicho personal se entrenaba para servir en Corea, cuando ya el armisticio acordado en julio del año anterior no exigía tanta preparación de combate. Su explicación de los hechos resulta original: "a un soldado se le disparó el arma. El proyectil, al rebotar en el asfalto, hirió al sargento reemplazante de la sección, que cayó a tierra. La tropa se sintió atacada y el fuego se desencadenó sin orden". El Tiempo, junio 25 de 2004. El relato que la Embajada Americana despachó al Departamento de Estado señaló a los soldados de "disparar contra los estudiantes que se replegaron y se dispersaron. Entre los soldados habían mujeres y, de acuerdo con varios observadores, estaban desarmados". Junio 10 de 1954. ANEU. $721.00(\mathrm{~W}) / 6-1054$, RG 59

45 El Espectador, agosto 4 de 1954.

46 La decisión fue aplaudida por la Embajada de Estados Unidos: "nuestro programa de perseguir subversivos, y aprobar una legislación anticomunista, ha tenido influencia en el gobierno colombiano". "La posición del presidente Rojas es sumamente clara". En el mismo documento criticó a El Tiempo por cuestionarla: "no entienden los métodos ni el peligro de la penetración comunista". Septiembre 14 de 1954. ANEU. 721.3/9-1454, RG. 59. En aplicación a lo resuelto por la Asamblea, Colombia negó el ingreso del poeta Pablo Neruda. partamentales y Consejos Municipales por cuerpos administrativos.

Las relaciones con industriales y comerciantes fueron muy fluctuantes y estuvieron signadas por la negociación constante. En busca de fondos para atender sus proyectos, Rojas creó el impuesto denominado "Cuota de Rehabilitación y Fomento", equivalente al $20 \%$ de los tributos liquidados en 1952. La Andi aceptó a regañadientes, pero negoció plazos para su pago. Al fin y al cabo, la entrega de los guerrilleros del Llano, lo justificaba.

La tolerancia de industriales y comerciantes no fue igual frente a las nuevas normas tributarias y la inclusión de un impuesto sobre las acciones en las sociedades anónimas, decretado a partir de 1954 para cubrir el déficit fiscal, impulsar la construcción de vivienda y financiar a las Fuerzas Armadas: los índices en las bolsas de valores se derrumbaron y el Ministro de Hacienda llamó al acuerdo. Las medidas tributarias se moderaron pero se mantuvo el gravamen sobre las sociedades anónimas.

Las tensiones continuaron con el anuncio posterior de nuevos impuestos y fuertes presiones de industriales y comerciantes para suspenderlos. Las decisiones gubernamentales recibían a menudo el epíteto de demagógicas y se les asimilaba a los dictados del gobierno peronista en Argentina. La injerencia del Estado en la economía molestaba a los productores, a los comerciantes y a los cafeteros, cuya bonanza también fue gravada. La táctica de Rojas consistió en implementar por decreto los tributos y negociar después algunas concesiones cuando éstos fueran cuestionados por los empresarios. ${ }^{47}$

Rojas se mostró en diversas ocasiones inflexible con los gremios, pero cedió a favor de ellos en muchos otros casos. A pesar de sus medidas, las ganancias de los empresarios mantenían sus índices y sus balances eran satisfactorios. Por otra parte, la creación del Banco Hipotecario Popular, el "Secretariado de Acción Social”-SENDAS-, la policía femenina y la fundación del Instituto Nacional de Abastecimiento -INA-, le trajeron respaldo popular.

47 Véase Eduardo Sáenz Rovner. Colombia años 50. (2002), p.156. Industriales, política y diplomacia. Bogotá: Universidad Nacional. 
La perspectiva apuntaba, entonces a organizar y dirigir el sindicalismo con la creación de la 'Confederación Nacional de Trabajadores' -CNT-, e impulsar su propio movimiento político: el 'Movimiento de Acción Nacional' -MAN-.

El reto fue inaceptable para los partidos, quienes giraron a la oposición. Para los liberales, el régimen se acercaba al totalitarismo y para el conservatismo la decisión de un nuevo movimiento con los socialistas era descalificable. Rojas se entronizaba en el poder e incumplía su promesa de permanencia transitoria. La Iglesia, por otra parte, sentía amenazada su influencia en la Unión de Trabajadores de Colombia-UTC-, y la élite económica se declaraba sorprendida por los anuncios de un movimiento "conservador, liberal y socialista contra las oligarquías resentidas" que se inspiraba en el binomio "pueblo-fuerzas armadas".

Las contradicciones se agudizaron y los periódicos liberales sufrieron de nuevo la censura hasta llegar al cierre48. Una torpeza hirió de gravedad al régimen: la arremetida brutal de un poderoso núcleo de detectives contra los asistentes a una corrida de toros. El suceso, a menudo, ha sido ampliamente referido por las fuentes sin recordar su preámbulo. Ocho días antes, el público taurino aplaudió el ingreso de Alberto Lleras Camargo y abucheó a la hija de Rojas. Según algunos autores, Rojas decidió "enseñar una lección al público" y orientó adquirir un grueso número de entradas para sus agentes en la próxima corrida. En efecto, éstos la emprendieron contra los presentes el 5 de febrero de 195649. Lo que sólo se conoció muchos años después, es que para la primer corrida, aquella en donde se aplaudió a

48 Los episodios en torno a la censura y cierre de los periódicos El Tiempo y El Espectador, así como la aparición de periódicos como El Intermedio y El Independiente, son minuciosamente narrados por Silvia Galvis y Alberto Donadío. El Jefe Supremo. (1988), pp.293-380. Bogotá: Planeta. La censura del periódico El Relator de Cali, es menos mencionada por la bibliografía nacional. Ella se debió a las denuncias que el periódico presentó ante las acciones de León María Lozano en Tulúa. La Embajada de Estados Unidos descalificó el cierre de El Tiempo y el Secretario de Estado Asistente para América Latina expresó personalmente su disgusto y el de la prensa norteamericana al general Rojas. ANEU. 721.11/9-355 y FRUS 19551957, vol. II, p. 892. En diversas ocasiones, Estados Unidos expresó también su rechazo por la persecución a los protestantes.

49 Silvia Galvis y Alberto Donadío. op. cit., pp. 467 - 471.
Lleras, los hijos de Eduardo Santos también habían comprado boletas para distribuir entre sus simpatizantes con ese objetivo.

Para entonces, el carácter transitorio del gobierno de Rojas se convirtió en indefinido; no se autovislumbraba como puente para facilitar el retorno de la democracia y los partidos, sino como gobierno perenne con el apoyo militar y en busca del respaldo popular. La Asamblea Nacional Constituyente no fue convocada para 1955 y la oposición se agudizó. La situación económica tampoco ayudó a Rojas: el precio del café cayó en el mercado internacional y la balanza de pagos se desequilibró, la inflación se disparó, el peso se devaluó frente al dólar y la reserva de divisas cayó. Rojas ganó la enemistad de los bancos con su política fiscalista y las facilidades de crédito que impuso en los bancos estatales, pero tuvo que ceder ante las ingentes presiones. El Banco Mundial y el FMI le obligaron a reducir las importaciones oficiales, a aumentar el encaje bancario y a prohibir los almacenes de depósito por parte de los bancos, entre otras medidas. La oposición de los empresarios arreció.

Tras el fracaso del MAN y de la CNT, Rojas lanzó como estrategia, el impulso a la 'Tercera Fuerza'50. Fue su respuesta al "Frente Civil" acordado por el liberalismo y la fracción laureanista del Partido Conservador, que amenazaba con arrastrar en contra del gobierno a toda la élite política y económica. Prácticamente aislado, Rojas tuvo que acudir a las Fuerzas Militares como sostén de primer orden. A ellas, precisamente, las involucró en la construcción del movimiento e instruyó al Ministro de Guerra, a los gobernadores y a los alcaldes militares para que tomaran parte activa en su organización ${ }^{51}$. El general Rafael Calderón fue nombrado "Jefe del Estado Mayor de la Tercera Fuerza", al tiempo que varios oficiales se convirtieron en sus propagandistas e impulsores. Los más altos oficiales juraron "luchar hasta la muerte por la supremacía de la Tercera Fuerza”.

50 Carlos H. Urán. 0p. cit., p. 90.

51 La República, junio 29 de 1956. 
Aunque el hecho empezó a generar malestar en algunos sectores de las Fuerzas Militares, su compromiso gubernamental parecía contar con bases más profundas que el simple "espíritu de cuerpo". En primer lugar, los oficiales del Ejército habían copado ya los principales espacios clientelistas de la política tradicional. Ahora, con la 'Tercera Fuerza' y los llamados 'Planes de Rehabilitación', dependían de los militares los empleos y las obras públicas, así como la prestación de indispensables servicios del Estado. En segundo lugar, no pocos oficiales, incluida la familia presidencial, parecían ajenos a la corrupción ${ }^{52}$.

La más importante constancia histórica de ello quedó plasmada en Relato de un Náufrago, una serie de artículos escrita para el periódico El Espectador por Gabriel García Márquez en abril de 1955 sobre el naufragio de ocho miembros de la tripulación del destructor "Caldas" de la Armada Nacional. La embarcación no expulsó a los marinos en medio de una tempestad; el bandazo de la nave se debió a la carga mal estibada que viajaba en cubierta. ¿Carga en un destructor? Sí: neveras, televisores y lavadoras

52 Según el proceso posterior adelantado en el Senado contra Rojas, el patrimonio bruto de su familia pasó de $\$ 190.000$ en 1952, a $\$ 8.000 .000$, aproximadamente, en 1956. En su defensa, Rojas lo atribuyó a los "obsequios" que la ciudadanía le entregaba a lo ancho y largo del país. Los acusadores señalaron a Rojas por vender carne de sus hatos a las Fuerzas Armadas y de obtener provecho con millonarios préstamos en la banca pública sin garantías suficientes. Rojas Pinilla ante el Senado. El proceso, vol. II, pp. 31-43. Aunque la censura de prensa no permitió las denuncias frente a las irregularidades, el imaginario popular fue creando infinidad de formas para expresar la inconformidad frente a hechos palmarios. El humor, por ejemplo, fue una de ellas: “Papá, papá, dice María Eugenia: tengo tierra en las uñas. Cérquela, mija, cérquela, qué espera, responde el general". Consúltese, al respecto "El 10 de mayo o de cómo los chistes, las parodias y los cuentos tumbaron una dictadura". Medellín: (s.p.i.), 1957. Revistas extranjeras como Time suplieron a los medios nacionales. Según la publicación del 16 de julio de 1956, Rojas se había convertido en el primer ganadero del país con nueve grandes haciendas y miles de cabezas de ganado. Con respecto a los militares, dijo en febrero 5 de 1957: "se rodearon de toda clase de comodidades, como equipos importados de televisión, alimentos enlatados y un club de oficiales fabulosamente lujoso... Encontraron fácil la obtención de préstamos para sus negocios, recibieron comisiones al efectuar negocios militares y usaron los obreros del gobierno en sus haciendas". Alberto Donadío ha dedicado un libro a la corrupción durante el gobierno de Rojas: El uñilargo. (2003). Medellín: Hombre nuevo editores. Para Diego Montaña, la dictadura develó a los militares como "agresivos latifundistas". Colombia, país formal y país real. (1963). Buenos Aires: Platina. de contrabando: "el destructor llevaba mal amarrada una carga política y moral" 53 .

\section{La caída}

El "Frente Civil" ya no tenía reversa. Buscando definiciones concretas, Lleras Camargo se reunió con Laureano Gómez en la ciudad de Benidorm. El propósito: impedir la reelección de Rojas y acelerar su caída. La declaración, suscrita el 24 de julio de 1956, recomendó una "acción conjunta destinada a conseguir el rápido regreso a las formas institucionales de la vida política y a la reconquista de la libertad y las garantías". En forma novedosa, los dos jefes políticos separaron a Rojas del conjunto de las Fuerzas Armadas, buscando la neutralidad o apoyo de estas últimas:

El retorno a la normalidad jurídica, vivamente ansiado por todos los partidos, traerá el retorno de las Fuerzas Armadas a la misión que desempeñaron con honor y satisfacción general en el tiempo inmediatamente pasado, como guardianes de los intereses internacionales y del orden interno y como ejecutores fieles de la autoridad escogida por el pueblo. La situación actual destruye todo equilibrio entre el jefe omnipotente e irresponsable de la clase armada y el resto del pueblo, y aún todavía, entre tal jefe y el conjunto de la fuerza pública, porque pone a oficiales y soldados al servicio ciego de una sola persona que arrogándose la totalidad del poder desprestigia con sus procederes autocráticos a la institución que dice representar y quita a la disciplina militar el nobilísimo carácter que tiene cuando no está dedicada al servicio personal de un hombre, sino a la tutela de las libertades y los derechos de todos los ciudadanos ${ }^{54}$.
53 Gabriel García Márquez.(1987). Relato de un náufrago. Bogotá: Oveja Negra. Según Tad Szulc: “Las denuncias sembraron inconformidad en importantes círculos militares para quienes Rojas deshonraba a las Fuerzas Armadas con su inmoralidad y deshonestidad". Entre ellos se contaba el general Luis Ordóñez. Véase: Twilight of the tyrants. (1959), p. 229. New York: Henry Holt.

54 Declaración de Benidorm. Laureano Gómez y Alberto Lleras, julio 24 de 1956. 
Como se sabe, la oposición obtuvo un severo impulso con la insólita explosión del 7 de agosto de 1956 en la ciudad de Cali. Originada en un descuido del Ejército, que parqueó camiones cargados con explosivos en la calle sin aviso alguno, fue tratada por Rojas como "sabotaje de la oposición".

Según algunos autores, la magnitud del hecho produjo manifestaciones de descontento en las Fuerzas Militares 55 . No obstante, la confianza de los uniformados ante Rojas fue advertida de nuevo por el General París en enero de 1957: "Rojas Pinilla, presidente 1958-1962, por decisión inmodificable de las Fuerzas Armadas" 56. El "Frente Civil" creció en afectos y a él se unieron Ospina, Urdaneta y Guillermo León Valencia. La Iglesia, con su cardenal Crisanto Luque asumió una posición beligerante contra Rojas. El 20 de marzo de 1957 se firmó el pacto definitivo contra la reelección de Rojas. Los partidos políticos liberal y conservador se comprometieron a:

Crear un gobierno civil que se ejerza a nombre de los dos partidos, que los represente por igual, en el cual ambos colaboren y que esté sostenido por una sólida alianza que no permita su naufragio ni lo deje inclinarse hacia la hegemonía ${ }^{57}$.

Los expresidentes en su totalidad, las direcciones de los partidos liberal y conservador, los gremios y la iglesia, exigieron la salida de Rojas. Un sector del conservatismo y la llamada "Dirección Nacional Liberal Popular", continuaron apoyando a Rojas, junto a la Confederación de Trabajadores de Colombia -CTC- y diversos sindicatos de base. Sin embargo, el bloqueo económico, la movilización estudiantil y, por último, el paro patronal y bancario promovido por Fenalco y la Andi, con la orientación de Alberto Lleras, alcanzaron su objetivo el 10 de mayo de 1957.

55 Willy, Muri. (1975). L'armée colombienne, étude d'une institution militaire dans ses rapports avec la societé en transition. 1930-1974, p.71. Thèse, Université de Paris V.

56 Diario Oficial, enero 26 de 1957

57 Pacto del 20 de marzo. Alberto Lleras y Mariano Ospina, 1957.

\section{El último embate}

La composición de la Junta Militar que le sucedió en el cargo fue decidida por el propio Rojas: Gabriel París, Rafael Navas, Luis Ordóñez, Deogracias Fonseca y Rubén Piedrahita. La historia debate si la Junta fue creada con el propósito de restablecer al General cuando las condiciones de gobernabilidad lo permitieran, o si fue instaurada de manera momentánea en el poder para asegurar la realización inmediata de elecciones presidenciales, como el mismo Rojas lo ordenó en su alocución de retiro.

Lo cierto es que Rojas escogió a sus más leales comandantes y aseguró en puestos claves de las Fuerzas Armadas a sus seguidores. Diversos testimonios describen la confianza del General por su regreso y el disgusto por la deslealtad y la traición de "los quíntuples" cuando finalmente avalaron el retorno de los partidos al escenario de la política nacional y del poder.

Rafael Navas Pardo, el hombre fuerte del gobierno más cercano a Rojas, y Luis Ordóñez, el comandante del servicio de inteligencia, fueron señalados mucho tiempo después por el presidente de la Junta, Gabriel París, de intentar un golpe de cuartel a mediados de 1957. En su concepto, sin embargo, no era un golpe para restaurar a Rojas: Navas encabezaba el intento para asumir el poder con toda su ambición ${ }^{58}$. Las intenciones de Navas fueron abortadas cuando los demás miembros de la Junta descubrieron el montaje de una emisora clandestina y ordenaron la detención de oficiales afectos a Navas ${ }^{59}$.

Alberto Duarte Blum, el Comandante del Ejército en época de Rojas y Ministro de Justicia, fue separado de su cargo por la misma Junta, que lo relacionaba con rumores de revuelta en noviembre de 1957 para impedir la votación del plebiscito que aprobó al Frente Nacional. En marzo de 1958, tres capitanes; Gabriel Puyana, Guillermo Rodríguez y José Jaime Rodríguez, procuraron liderar un golpe que instau-

58 París, Gabriel. Declaraciones concedidas al periódico El Tiempo, Lecturas Dominicales, octubre de 1996.

59 Téllez, Edgar y Sánchez, Álvaro.(2003). “Ruidos de sables”. Bogotá: Planeta. 
rara una nueva Junta compuesta por los coroneles Alberto Ruiz Novoa, Gabriel Revéis Pizarro y Gerardo Ayerbe Chaux. El movimiento, que consultó a Lleras Camargo, fue desalentado por su rechazo. En abril de 1957, varios coroneles propusieron a Navas Pardo que continuara en el poder. En su criterio, los civiles no estaban preparados para asumir el mando y libraban una campaña para desprestigiar a las Fuerzas Armadas. El entonces mayor Âlvaro Valencia Tovar se opuso a la idea, y Navas Pardo opinó que no estaba dispuesto a perpetuarse en el gobierno.

El último intento se ejecutó el 2 de mayo, dos días antes de las elecciones presidenciales, encabezado por el Comandante del Batallón Número 1 de Policía Militar, coronel Hernando Forero Gómez, quien creía contar con el apoyo de Ordóñez y Navas, del Director de la Policía Quintín Gómez, del Comandante de la Fuerza Aérea Alberto Pawels, y de numerosas guarniciones del país. Rojas Pinilla, entre tanto, esperaba el desenlace de los hechos en Santo Domingo, para trasladarse de inmediato a Bogotá y reasumir el poder.

El plan del golpe consistió en detener a los cinco miembros de la Junta, al Comandante del Ejército Iván Berrío, y al virtual presidente Alberto Lleras Camargo, controlar militarmente a Bogotá, garantizar el inmediato regreso de Rojas y obtener el apoyo de los militares en todo el país. Sin embargo, falló porque no pudieron localizar al almirante Rubén Piedrahita y porque el oficial de policía, encargado de detener a Lleras, defeccionó y terminó entregándolo por error a una patrulla leal del Batallón Guardia Presidencial.

Con el fracaso del movimiento y el asilo político de la mayoría de los participantes, entre los cuales se encontraba el posteriormente célebre teniente Alberto Cendales, Alberto Lleras Camargo fue elegido presidente con 2.482.984 votos, frente al candidato opositor al Frente Nacional, Jorge Leyva, quien obtuvo 614.816 sufragios. Con ese abultado resultado, la legitimidad rodeó al nuevo presidente quien, días más tarde, el 15 de mayo dirigió a los militares el recordado discurso del Teatro Patria:

La política es el arte de la controversia por excelencia. La milicia, el de la disciplina. Cuando las
Fuerzas Armadas entran a la política, lo primero que se quebranta es su unidad porque abre la controversia en sus filas. El mantenerlas apartadas de la deliberación pública no es un capricho de la Constitución, sino una necesidad de su función. Si entran a deliberar entran armadas.

La política mina la moral y la disciplina de las Fuerzas Armadas que al transgredir el límite de sus funciones entran a la política y la dañan. La dañan porque nadie las invita a entrar a la política, sino con el ánimo de que echen bala por su cuenta, pongan los muertos, destruyan a sus enemigos y defiendan intereses ajenos a las conveniencias generales de la República. Al término de las extralimitaciones, las Fuerzas Armadas regresan a su oficio primitivo rodeadas de adversarios, sin prestigio, sin gloria y sin amigos.

Yo no quiero que las Fuerzas Armadas decidan cómo se debe gobernar a la nación en vez de que lo decida el pueblo, pero tampoco que los políticos decidan cómo se debe manejar a las Fuerzas Armadas en su función técnica, en su disciplina, en sus reglamentos, en su personal. Las dos invasiones son funestas, pero en cualquier caso salen perdiendo las Fuerzas Armadas ${ }^{60}$.

Se abrieron así las puertas de un nuevo pacto y una nueva relación entre civiles y militares que se profundizarán a lo largo del Frente Nacional.

\section{Conclusiones}

En 1953, en el momento en que Gustavo Rojas Pinilla produce el llamado "golpe de opinión" en Colombia, trece de los veinte Estados latinoamericanos se hallaban bajo el poder marcial. Algunos más, como Bolivia, tenían un presidente civil pero de facto. En muchos de ellos, la constitución se encontraba interrumpida o no contemplaba procesos de elección y sucesión presidencial. Al generalizar las circunstancias, el golpe de Estado propinado por Rojas ha sido analizado muchas veces como parte de la irrupción que los militares protagoni-

60 Citado por Tellez y Sánchez. Op. cit., pp. 26 y 27. 
zan con respecto a la política y el poder en todo Latinoamérica.

Sin embargo, vale la pena detenerse en una breve referencia a otros procesos seguidos por ejércitos del continente cuya semejanza se busca con el carácter de la jefatura y concepción de Rojas, para captar de inmediato sus visibles diferencias.

En el caso de Argentina, a diferencia de Colombia, los militares parecen haber sido formados para una misión social y política de trascendencia. Precisamente, una investigación de Alain Rouquié percibe desde 1918 las "fórmulas audaces y prematuras" que constituirán el "leitmotiv" del intervencionismo militar. Es más, en un discurso concreto del director del Colegio Militar de Buenos Aires, Rouquié encuentra en 1920 los elementos de un mesianismo subyacente al posterior activismo militar61.

En las filas de los oficiales argentinos creció la autoconcepción de una casta militar compuesta por los "elementos más puros de la sociedad" 62 , cuyo sueño será materializado por el nacionalismo popular peronista. Por consiguiente, en lugar de las élites, el 17 de octubre de 1945, fue una enorme masa de "descamisados" quien exigió en la histórica Plaza de Mayo la presencia del coronel Juan Domingo Perón en el poder. Los militares argentinos, desde entonces, comprendieron que tenían la capacidad para asumir por sí solos el poder, aplastando a los partidos tradicionales, si contaban con el apoyo popular63.

El "tenientismo" de 1922 en Brasil, por su parte, expresa el surgimiento de una nueva y joven élite

61 Alain Rouquié. (1978). Pouvoir militaire et societe politique en Republique Argentine. Paris, Presses de la Fondation Nationale des Sciences Politiques. Op. cit., p. 73.

62 Juan R. Beltrán. “Misión del oficial frente a los problemas sociales contemporáneos". En: Revista Militar, septiembre de 1936, p. 499513. Buenos Aires.

63 Finalmente, la tendencia será llevada al extremo por el golpe de Onganía el 28 de junio de 1966: "se disolvió el parlamento -el presidente concentró en sus manos los dos poderes-y también los partidos políticos, cuyos bienes fueron confiscados y vendidos, para confirmar lo irreversible de la clausura de la vida política". Cf. Luis Alberto Romero. Breve historia contemporánea de Argentina. (1994). México, FCE. Más consistente con el nuevo papel de los militares será el golpe del 24 de marzo de 1976, ejecutado por Videla, Massera y Agosti, reconocidos hoy por su intento de silenciar a la sociedad entera. militar descontenta frente a un ejército anacrónico incapaz de castigar la corrupción del cacicazgo regional y de asumir la renovación de las instituciones públicas. Los militares apoyan el "Estado Novo" de Getulio Vargas y sus proyectos de modernización e industrialización. Juegan, a partir de esta coyuntura, un papel "moderador" sobre la crónica inestable del sistema político. Derrocan gobiernos sin asumir en ningún caso el poder y se movilizan en función del "progreso" del país ${ }^{64}$. Inmersos en este proceso, desarrollan una sofisticada ideología corporativa que fundamenta la doctrina de seguridad nacional y los insta a dirigir el Estado por encima de los civiles, a partir de 1964.

En Colombia, por el contrario y tal como opina Marco Palacios (autor y analista político), el término "militar" que califica al gobierno de Rojas requiere precisiones. "La legitimidad inicial del régimen provino de su proyecto de pacificación y reconciliación nacional" 65 . Además, el gobierno se instaló sobre las bases partidistas del conservatismo ospino-alzatista, en tanto que la élite liberal aduló a Rojas con los títulos de "Salvador de la Patria" y "Libertador". La incertidumbre de Rojas por acceder o no al poder fue resuelta, como atrás se dijo, con la participación dramática pero fundamental de los civiles, quienes además decidieron las cabezas de los ministerios.

Si bien el gasto militar y de policía creció durante su período, el gobierno de Rojas no fue tampoco una dictadura recalcitrante. Proscribió al Partido Comunista, pero no persiguió con saña y a muerte a sus militantes. Cerró los periódicos El Tiempo y El Espectador, pero permitió que El Intermedio y El Independiente aparecieran en su reemplazo. Cuando recién se perfilaba con proyecto político propio, recibió la oposición de todos los sectores que lo habían entronizado y se inició su derrumbe.

De modo que, si bien el gobierno de Rojas perfiló a los militares en funciones políticas que no habían

64 Véase Alfred Stepan. (1971). Brasil: Ios militares y la política. Buenos Aires: Amorrortu Editores.

65 Marco Palacios. (1995). Entre la legitimidad y la violencia. Colombia, 1875-1994, p.211. Bogotá: Norma. 
disfrutado hasta entonces, no perdió la decisoria influencia civil, partidista y eclesiástica que le dio origen. Cuando ciertos rasgos peronistas aparecieron en el General con la organización del Movimiento de Acción Nacional -MAN-y la creación de una nueva central sindical, la Confederación Nacional de Trabajadores -CNT-, las mismas facciones civiles que lo llevaron al gobierno le declararon la oposición. En

\section{Bibliografia}

Abella, A. (1973). Así fue el 13 de junio. Bogotá: Aquí Bogotá.

Alape, A. (1984). La paz, la violencia, testigos de excepción. Bogotá: Planeta.

Arciniegas, G. (1954). Entre la libertad y el miedo. Santiago de Chile: Editorial del Pacífico.

Atehortúa, A. (1995). El poder y la sangre. Las historias de Trujillo - Valle. Bogotá: Cinep, Universidad Javeriana Cali.

Ayala, C. (1991). "El discurso de la conciliación: análisis cuantitativo de las intervenciones de Gustavo Rojas Pinilla entre 1952-1959", Anuario Colombiano de Historia Social y de la Cultura, n. ${ }^{\circ}$ s 18-19. Bogotá: Universidad Nacional, Departamento de Historia.

Azula B., R. De la revolución al orden nuevo, Bogotá: Kelly, (s.f).

Bayona, R. (1984). Recuerdos de un ochentón. Bogotá: Editorial Nelly.

Belmonte, P. L. (1954). Antecedentes históricos del 8 y 9 de junio. Bogotá: Imprenta Nacional.

Beltrán, J. R. (1936). "Misión del oficial frente a los problemas sociales contemporáneos". En: Revista Militar. Buenos Aires :

Díaz, A. (1948). Los Verdugos del Caudillo y de su pueblo. Bogotá: ABC.

Donadío, A. (2003). El uñilargo. Medellín: Hombre nuevo editores.

Escobar, A. (1957). En el salón de los virreyes. Testimonio civil de un golpe militar. Bogotá: Kelly.

Forero, A. (1993). Momentos y perfiles de la historia de Colombia. Bogotá: Banco de la República: Uniandes. mayo de 1957, por orden patronal, bancos y fábricas cerraron. Los estudiantes se manifestaron en la calle y paralizaron el transporte urbano. Entonces, sin resistencia, Rojas depositó el gobierno en una junta integrada por cinco generales de extracción conservadora que propició el regreso del bipartidismo en medio de constantes dudas y conatos de restauración de Rojas o golpes de cuartel.Д.

Galvis, A. (1976). Memorias de un político centenarista. Bucaramanga: Impresores Colombianos.

Fluharty, V. (1981). La Danza de los Millones. Régimen Militar y Revolución Social. Bogotá: El Ancora.

Franco I., E. (1976). Las Guerrillas del Llano. Medellín: Editorial Hombre Nuevo.

Galvis, S. y Donadio, A. (1986). Colombia Nazi. Bogotá: Planeta.

Galvis, S. y Donadio, A. (1988). El Jefe Supremo. Bogotá: Planeta.

Gómez, Á. (1999). Pensando en ti, Margarita. Bogotá: Fundación Álvaro Gómez Hurtado.

García Márquez, G. (1987). Relato de un náufrago. Bogotá: Oveja Negra.

Lee Fluharty, V. (1981). La danza de los millones. Régimen militar y revolución social en Colombia (1930-1956). Bogotá: El Áncora editores.

Lleras R., C. “Crónicas de mi propia vida”, Nueva Frontera, Bogotá: n. 564 (diciembre 23-29, 1985).

Lleras R., C. (1955). De la república a la dictadura. Bogotá: Editorial Argra.

Montaña, D. (1963). Colombia, país formal y país real. Buenos Aires: Platina.

Montezuma, A. (1960). Comisión Instructora. El proceso contra Gustavo Rojas Pinilla ante el congreso de Colombia. Documentos compulsados y compilados por Gastón Valencia. Bogotá: Imprenta Nacional.

Muri, W. (1975). L’armée colombienne, étude d'une institution militaire dans ses rapports avec la societé en transition 1930-1974. Thèse, Université de Paris V.

Ospina, M. C.(1998). Doña Bertha. Bogotá: Planeta. 
Palacios, M. (1995). Entre la legitimidad y la violencia. Colombia, 1875-1994. Bogotá: Norma.

Paris, G. (1996). Declaraciones concedidas a "El Tiempo", Lecturas Dominicales, octubre de 1996.

Pécaut, D. (1987). Orden y Violencia. 1930-1954. Bogotá: Siglo XXI Editores.

Puyana, G. (1993). ¡Por la libertad en tierra extraña! Bogotá: Banco de la República.

Puyana, G. (2001). Vivencias de un ideal. Relatos que pueden ser historia. Bogotá: Editora Guadalupe.

Ramsey, R. (1981). Guerrilleros y soldados. Bogotá: Tercer Mundo.

Reyes, C. (1989). "El gobierno de Mariano Ospina Pérez". En: Nueva Historia de Colombia (NHC), Bogotá: Planeta, vol. II, capítulo 1.

Rojas, G. (1954). “Bienvenida a la Patria”. Saludo del General Rojas al regreso del Batallón Colombia, noviembre 30 de 1954. En: Mensajes y discursos. Bogotá, Imprenta Nacional.

Banco de la República - Uniandes. (1993). Rojas, Gustavo. "Las guerrillas en el Llano y otras cosas más", Revista de Historia, vol. 1, n. ${ }^{\circ}$ 1, agosto de 1975, p. 7, Bogotá.

Rojas, G. (1959). Rojas Pinilla ante el Senado. Bogotá, Excelsior.

Rojas, G. (1975). "Reportaje”. Revista de Historia, vol. I, n. ${ }^{\circ} 1$.

Rojas, M. E. (2000). Rojas Pinilla, mi padre. Bogotá: Panamericana.

Rouquié, A. (1978). Pouvoir militaire et societe politique en Republique Argentine. Paris: Presses de la Fondation Nationale des Sciences Politiques.

Sáenz, E. (2002). Colombia años 50. Industriales, política $y$ diplomacia. Bogotá: Universidad Nacional.
Serpa, J. (1999). Rojas Pinilla. Una historia del siglo XX. Bogotá: Planeta.

Sierra, G. (1954). Las guerrillas en los Llanos orientales. Manizales: Imprenta Departamental.

Szulc, T. (1959). Twilight of the tyrants. New York: Henry Holt.

Téllez, E. y Sánchez, Á. (2003). “Ruidos de sables”. Bogotá: Planeta.

Tirado M., Á. (1989). "El gobierno de Laureano Gómez, de la dictadura civil a la dictadura militar", vol. II, capítulo IV. En: Nueva Historia de Colombia, (NHC). Bogotá: Planeta.

Torres Del Río, C. (2000). Fuerzas Armadas y seguridad nacional. Bogotá: Planeta.

Torres, I. (1973-1974). Los Inconformes. Bogotá: Margen Izquierdo, Tomo III.

Urán, C. H. (1983). Rojas y la manipulación del poder. Bogotá: Carlos Valencia Editores.

Valencia T. Á. (1992). Testimonio de una Época. Bogotá: Planeta.

Valencia T, Á. (1976). "Sobre la guerra de Corea”, n. ${ }^{\circ} 19$. Alternativa. Bogotá.

Valencia, Á. y Sandoval, J. (2001). Colombia en la guerra de Corea. La historia secreta. Bogotá: Planeta.

Varela, D. F. (1998). Documentos de la Embajada. Bogotá: Planeta.

Vargas, A. (2002). Las Fuerzas Armadas en el conflicto colombiano. Bogotá: Intermedio.

Vásquez, A. (1992). Historia crítica del Frente Nacional. Bogotá: Foro Nacional por Colombia.

Villar Borda, C. (1953). El presidente Libertador. Bogotá: Iqueima. 